\title{
Mathematical Modeling of High Intensity Electric Arcs Burning in Different Atmospheres
}

\author{
Marco A. RAMíREZ-ARGÁEZ, ${ }^{1)}$ Carlos GONZÁLEZ-RIVERA" and Gerardo TRÁPAGA²) \\ 1) Department of Metallurgy, Chemistry Faculty, National Autonomous University of Mexico (UNAM), Edificio " $D$ " Circuito de \\ los Institutos s/n, Cd. Universitaria, Del. Coyoacán, 04510 México D.F., México. E-mail: marco.ramirez@servidor.unam.mx, \\ carlosgr@servidor.unam.mx $\quad$ 2) CINVESTAV-IPN Unidad Querétăro, Libramiento Norponiente 2000, Fraccionamiento \\ Real de Juriquilla Santiago de Querétaro, Qro. 76230, México. E-mail: trapaga@qro.cinvestav.mx
}

(Received on November 27, 2008; accepted on February 12, 2008)

\begin{abstract}
Previous works attempting to simulate DC arcs have assumed the plasma gas to be composed by $100 \%$ air, consequently, the arc region has been represented by solving the equations that govern the process, i.e. heat and mass conservation equations coupled to the turbulent Navier-Stokes equations. A real plasma gas is composed by a complex mixture of several gases, such as air (from environment), $\mathrm{CO}$ and $\mathrm{CO}_{2}$ (coming from decarburization and post combustion), $\mathrm{H}_{2} \mathrm{O}$ and $\mathrm{H}_{2}$ (from humidity) as well as metallic and non-metallic vapors coming from scrap melting. The real plasma composition is unknown, however, if air does not represent the atmosphere in which a DC arc burns, the following question arises: How is the arc being affected by burning in different atmospheres? To answer this question, in this work a mathematical model was developed to represent a DC arc burning in different gases such as nitrogen, argon, hydrogen, oxygen, $\mathrm{CO}_{2}$ and $\mathrm{CO}$. The model was used to study the effect of the gas composition on the electrical characteristics of the arc. It was found that air followed by $\mathrm{CO}$ and $\mathrm{CO}_{2}$ are the most efficient gases to melt and heat up the bath. Argon is a special case since has the highest conductivity and lowest heat capacity that would be very useful for long arc length applications.
\end{abstract}

KEY WORDS: electric arc; heat transfer; fluid flow; mathematical modeling.

\section{Introduction}

The Electric Arc Furnace (EAF) has been gaining acceptance as a steelmaking process and currently represents almost $40 \%$ of the total crude steel production in the world. ${ }^{1)}$ The main purpose of the EAF process is to produce molten steel from scrap, direct reduced iron (DRI), pig iron, and other raw materials. In this process heat is supplied to the steel bath through graphite electrodes, making it possible to melt and control the steel temperature. Considering the rather semi empirical development of this technology and taking into account the most recent trends in the industry showing that the efficiency of this process is reaching a plateau, ${ }^{2)}$ a fundamental understanding of the system may represent the only suitable way to address current key issues (e.g., energy and electrode consumption, productivity, electric energy consumption, etc.) affecting further developments in the process.

Currently, there are two alternative technologies in the EAF process, i.e., the Direct Current (DC-EAF) and its predecessor Alternate Current system (AC-EAF). It has been claimed that the DC system reduces the energy and electrode consumption, as well as the level of noise. However, it is now accepted that the major advantage of the DC furnace in comparison to the $\mathrm{AC}$ system is the prevention of the flicker effect (i.e. the DC arc is more stable). Currently, the DC technology covers approximately $70 \%$ of the new EAF being commissioned the last decade. ${ }^{3)}$

The increased use of DC EAF has promoted researchers to understand and optimize the process ${ }^{4)}$ Ushio et. al. ${ }^{5)}$ were pioneers in the mathematical modeling of electric body forces in the electric arc furnace (EAF). They developed a model to represent electromagnetic forces, flow fields and temperature gradients in the arc region for a DC-EAF, employing magneto hydro-dynamic equations. This model is limited due to the assumptions of both fixed values of some physical properties as well as the definition of electric parameters apriori. Szekely et al. ${ }^{6}$ ) improved the previous model, however, the effect of electromagnetic forces in the temperature field of liquid metal was not considered. Quian et $a l^{7)}$ conducted a Laplacian representation, computing fluid flow and heat transfer in the arc region; however the effect of induced current was not taken into account. Alexis et $a l .{ }^{8)}$ have reported some improvements to represent a DC-electric arc. They employed Maxwell's equations for the electromagnetic field and the turbulent fluid flow and heat transfer equations. The effect of the induced currents due to the high velocity motion of the electric conductor was also considered. In this work the arc structure is easily described. Ramirez and Trapaga ${ }^{9}$ fully investigated the shape of a DC electric arc, unambiguously defining a boundary of the arc region corresponding to the $10000 \mathrm{~K}$ isotherm, they reported that all physical properties in the arc can be obtained from the temperature field and also that 
the computation of current densities can be obtained from the magnetic field.

In the DC EAF, electromagnetic (EM) fields play a critical role in determining the plasma characteristics in the electric arcs sustained by the EM energy. The arc attachment on the electrodes is controlled by interactions of the EM fields with incoming cold gas. ${ }^{10)}$

It is believed that gas composition may play an important role in controlling heat transfer from the arc to the bath. Then, the objective of this work is to analyze how power is delivered and affected by the type of gas atmosphere between the electrodes in DC electric arcs. Steady state simulations of DC-Electric Arcs burning in atmospheres of air, argon, oxygen, nitrogen, $\mathrm{CO}$ and $\mathrm{CO}_{2}$ are presented in this work. Such a study has not been reported yet for electric arcs in EAF but for other arc systems such as GTA and TIG welding arcs some studies have already been reported. ${ }^{11,12)}$

\section{Mathematical Model of the Arc Region}

The general mathematical formulation of this model can be found elsewhere. ${ }^{8)}$ Here, only a brief summary of the mathematical formulation will be presented together with the discussion of some improvements of the model (due to space limitations). The most important simplifying assumptions considered in the model are: i) the arc is considered to be in Local Thermodynamic Equilibrium (LTE), ${ }^{13)}$ ii) the current density at the cathode is assumed to be constant for graphite cathode electrodes regardless the gas composition, and with a value of $4.4 \times 10^{7} \mathrm{~A} / \mathrm{m}^{2}$ based on available experimental measurements, $\left.{ }^{14}\right)$ iii) the bath surface is considered to be flat, iv) compressibility effects are neglected. The governing equations include: i) The continuity, ii) the turbulent Navier-Stokes equations, iii) the turbulent energy conservation equation which includes as source terms the Joule heating effect, the Thompson effect, and the radiation losses from the hot plasma, iv) the Maxwell's equations, v) Ohm's law (including a convective term), vi) the charge conservation equation, vii) the transport equations of the turbulent kinetic energy and energy dissipation rate, i.e. the standard $k-\varepsilon$ turbulence model. Regarding boundary conditions, the complete list required for all variables can also be found in. ${ }^{8)}$ An important part of the mathematical model is the representation of the regions close to the electrodes (cathode and bath surfaces). In those positions departure from LTE is established and special care is needed to represent the system. To represent the cathode region it is assumed that the voltage drop in that area can be related to a heat flux term denominated as the "cathode fall". At the anode, close to the bath region, the arc interacts with the bath. Three arc bath interactions are considered: heat flux from the arc to the bath, current density flux entering the bath and a shear stress due to the jet impinging on the bath. Actually, the pressure due to this impingement of the arc jet (causing a bath depression) is neglected in this study. The heat flux from the arc has four different contributions: a heat flux due to a voltage drop close to the anode named "anode fall", condensation of electrons, radiation, and convection. This model has been successfully validated against experimental measurements of temperature and velocity through data found in the literature for other arc systems
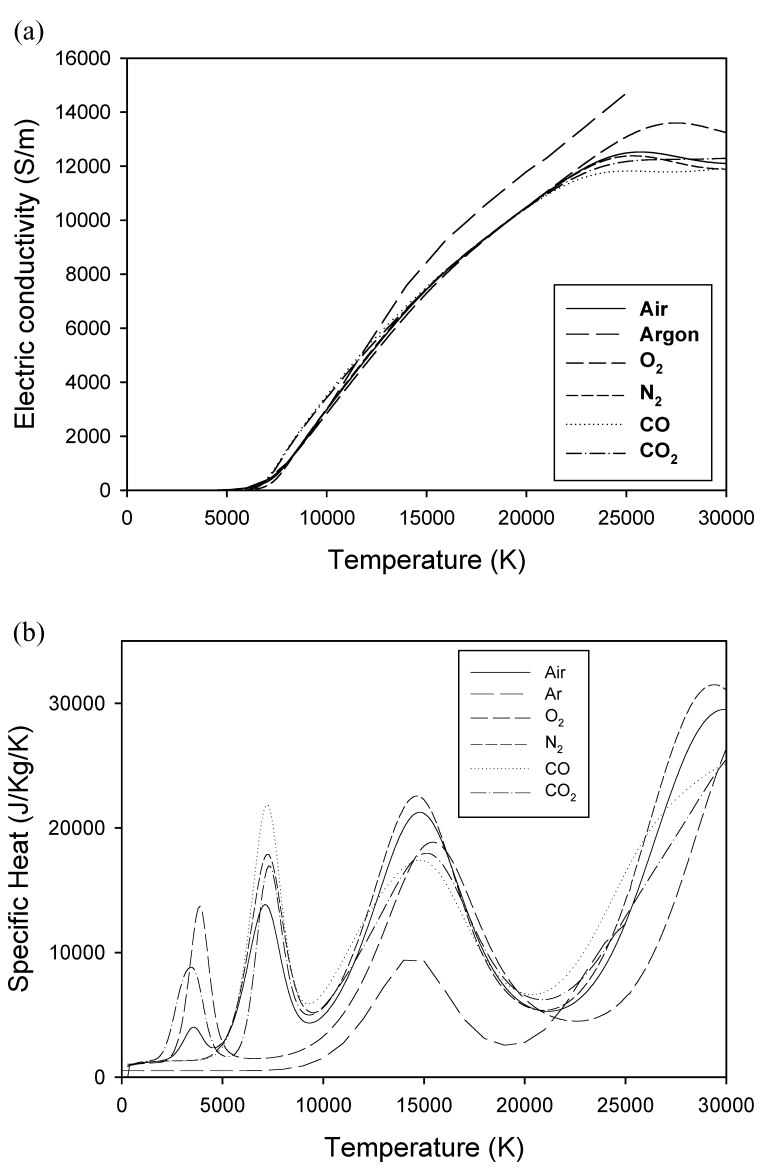

Fig. 1. Physical properties of different hot gases (air, argon, oxygen, nitrogen, $\mathrm{CO}$, and $\mathrm{CO}_{2}$ ). (a) Electric conductivity and (b) specific heat.

such as welding ${ }^{15,16)}$ and the details of the validation can be found in. ${ }^{17}$ )

Properties for plasmas of air, argon, oxygen, nitrogen, $\mathrm{CO}$ and $\mathrm{CO}_{2}$ were taken from Murphy et al. ${ }^{18)}$ and some of these are shown in Figs. 1(a) and 1(b) to present electrical conductivity and specific heat respectively for each gas.

All governing equations subjected to their corresponding boundary conditions were cast and solved simultaneously using the commercial CFD code PHOENICS 3.4 in a PC with a Pentium $4^{\circledR}$ processor. Computational domains of $60 \times 60$ grids were used and the calculations took around 3000 iterations to converge the set of equations into a solution, which was considered when all imbalances of the transport equations were lower than $1 \%$.

\section{Results and Discussion}

Figures 2(a) to 2(f) presents velocity vectors maps for arcs operating under the same length $(0.3 \mathrm{~m})$ and same current (44kA) but different atmospheres (a) air, (b) argon, (c) oxygen, (d) nitrogen, (e) $\mathrm{CO}$ and (f) $\mathrm{CO}_{2}$. All cases show a well developed plasma jet directed towards the bath driven by electromagnetic body forces mainly close to the cathode. The jets of air and oxygen expand more than the others while argon and nitrogen are less expanded and jets of $\mathrm{CO}$ and $\mathrm{CO}_{2}$ are expanded moderately. The expansive behavior of the jets may be explained by looking at the contours of turbulent kinematic viscosity depicted in Figs. 3(a) to 3(f) for the different plasmas (air, argon, oxygen, nitrogen, $\mathrm{CO}$ 

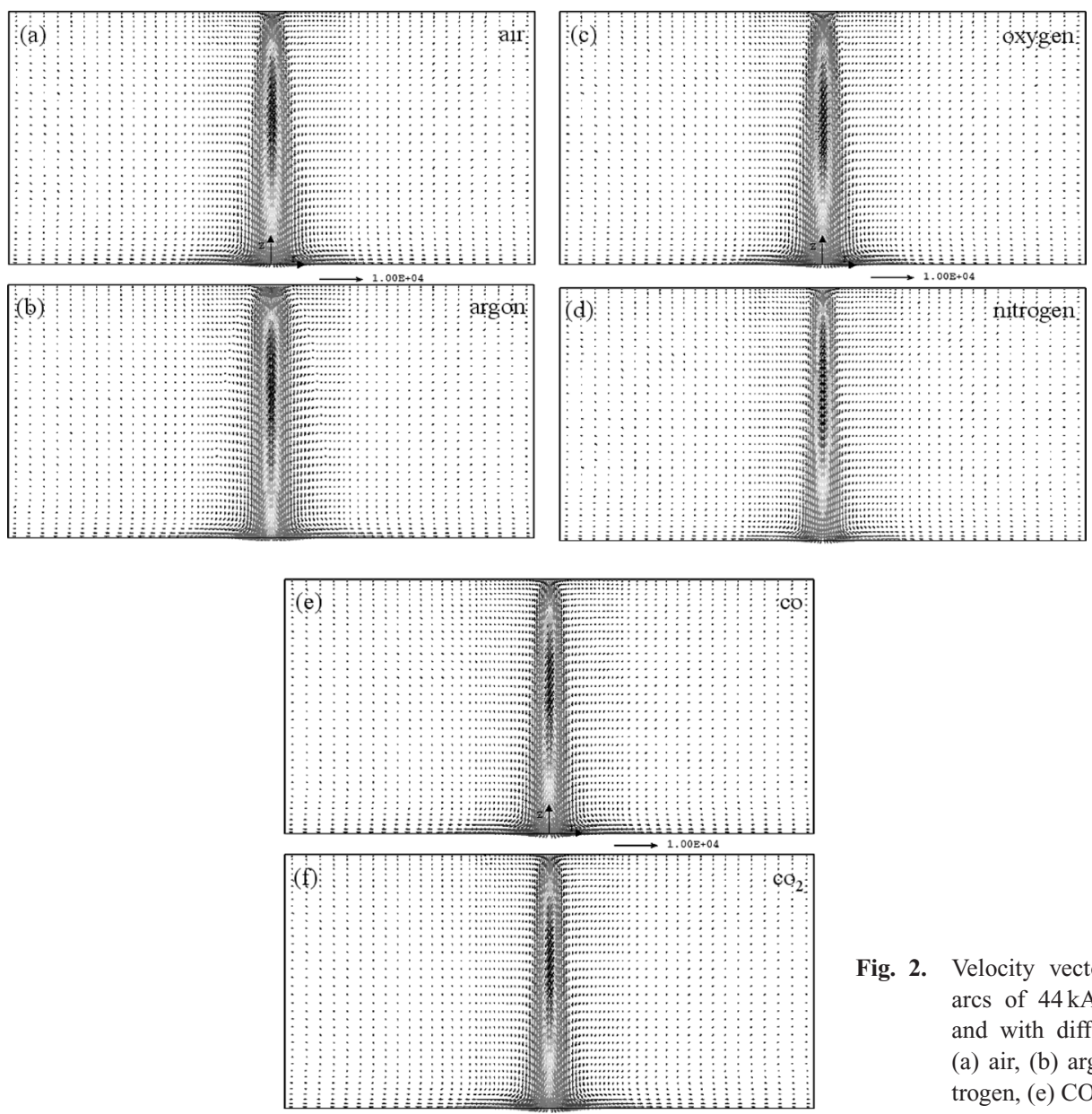

Fig. 2. Velocity vectors fields for electrics arcs of $44 \mathrm{kA}$ current, $0.3 \mathrm{~m}$ length and with different gas atmospheres: (a) air, (b) argon, (c) oxygen, (d) nitrogen, (e) $\mathrm{CO}$, (f) $\mathrm{CO}_{2}$.
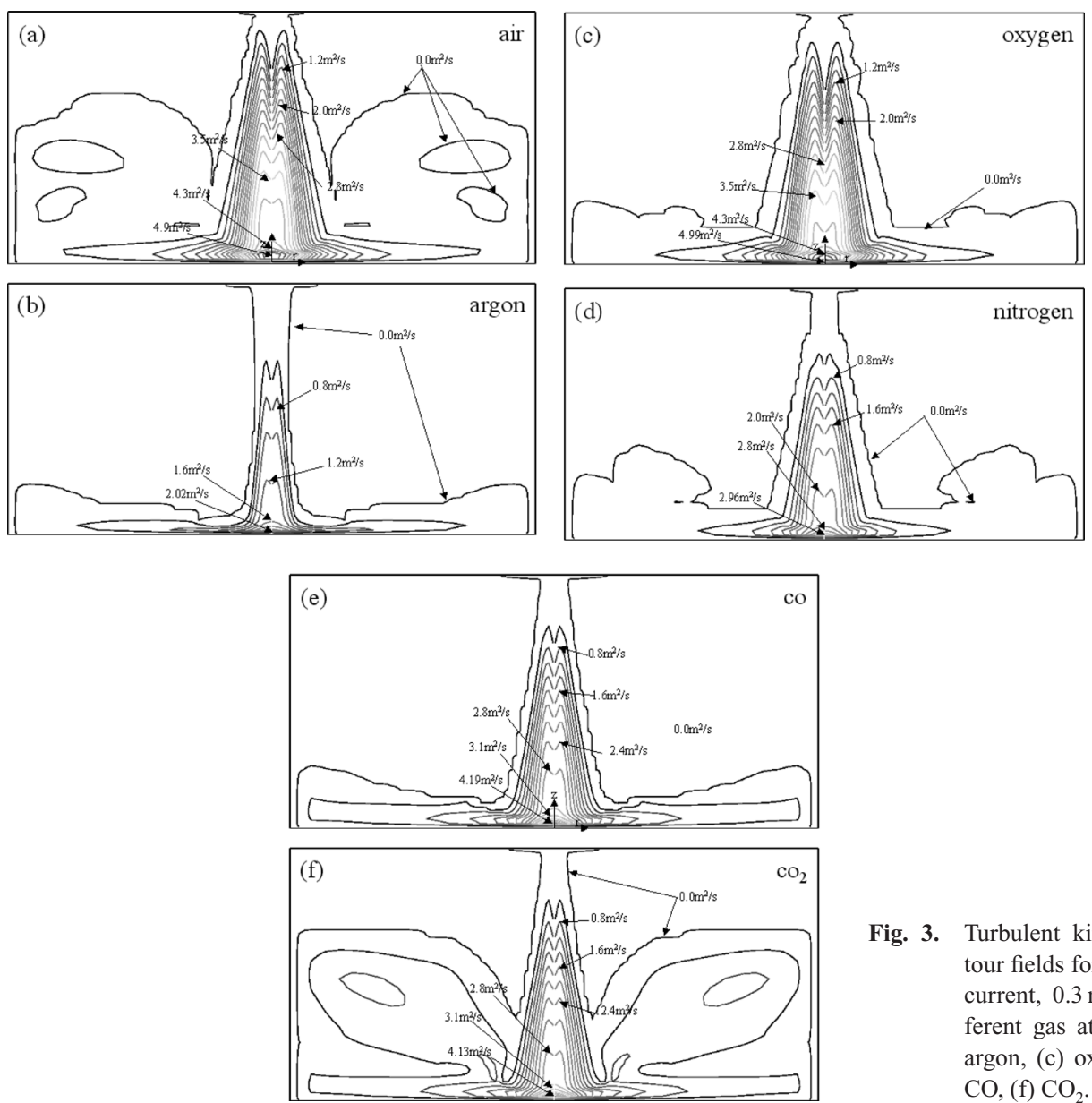

Fig. 3. Turbulent kinematic viscosity contour fields for electrics arcs of $44 \mathrm{kA}$ current, $0.3 \mathrm{~m}$ length and with different gas atmospheres: (a) air, (b) argon, (c) oxygen, (d) nitrogen, (e) $\mathrm{CO},(\mathrm{f}) \mathrm{CO}_{2}$ 

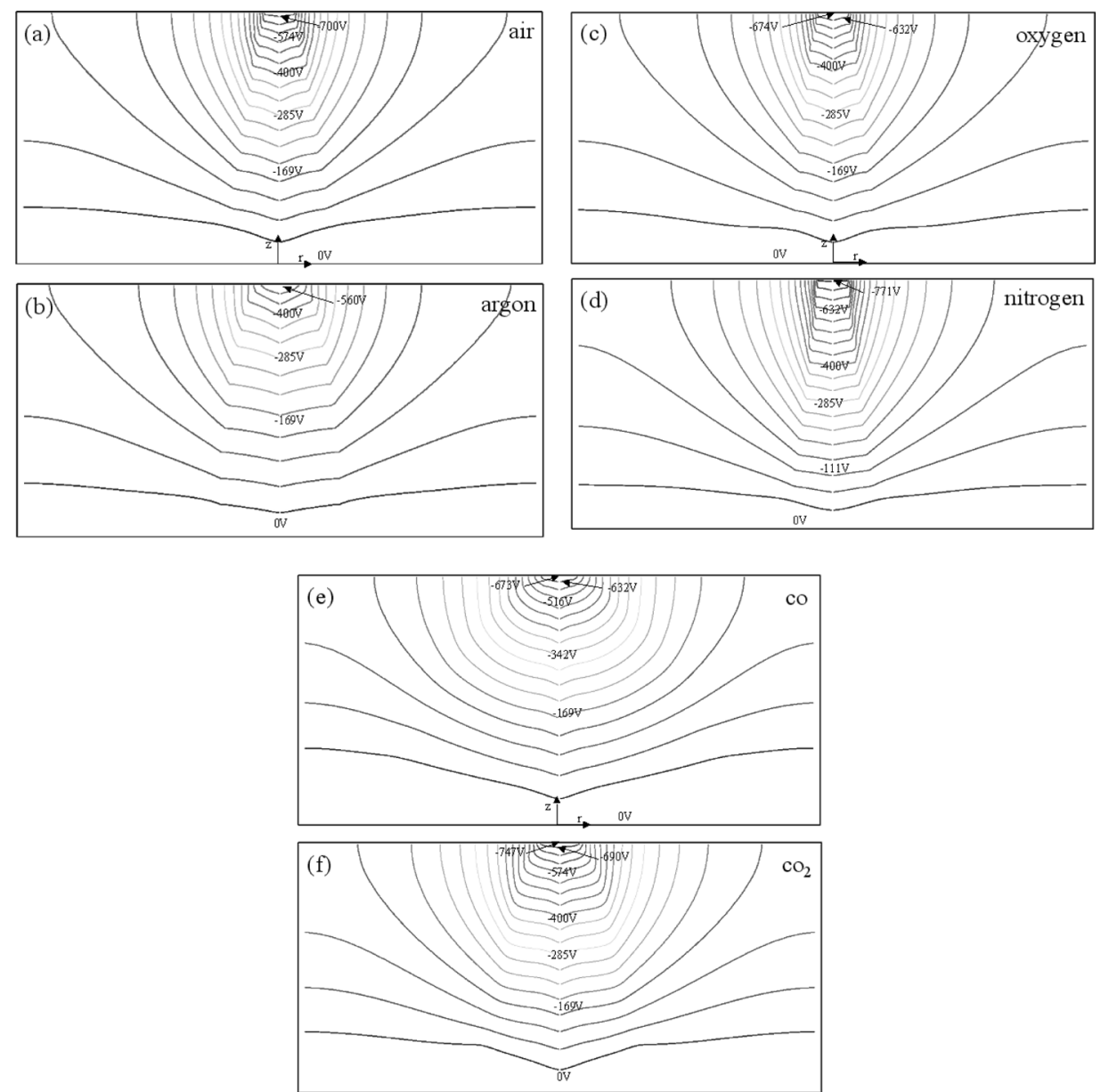

Fig. 4. Voltage contours for electrics arcs of $44 \mathrm{kA}$ current, $0.3 \mathrm{~m}$ length and with different gas atmospheres: (a) air, (b) argon, (c) oxygen, (d) nitrogen, (e) $\mathrm{CO}$, (f) $\mathrm{CO}_{2}$.

and $\mathrm{CO}_{2}$ ). Expansion results when gas out of the jet is entrained into it, which happens thanks to turbulence. Therefore, air and oxygen jets are more turbulent than $\mathrm{CO}$ and $\mathrm{CO}_{2}$ jets and the lowest turbulent jets are argon and nitrogen jets, which expand less.

Arc voltages keeping the same arc length and current ( $L=0.3 \mathrm{~m}$ and $I=44 \mathrm{kA}$ ) but varying the plasma composition are presented in Figs. 4(a) (air), 4(b) (argon), 4(c) (oxygen), 4(d) (nitrogen), 4(e) (CO) and 4(f) $\left(\mathrm{CO}_{2}\right)$. Air, $\mathrm{CO}, \mathrm{CO}_{2}$ and oxygen present similar voltages $(600-700 \mathrm{~V})$, while argon shows the lowest voltage $(560 \mathrm{~V})$ and nitrogen has the highest voltage $(770 \mathrm{~V})$. Voltage drop, at constant electric flow, is caused by the total ohmic resistance of the plasma, which depends on the electric conductivity and on the arc length, but since arc length is kept constant, then electric conductivity determines the voltage drop. Then, it seems clear that argon shows the highest conductivity, followed by similar conductivities of air, oxygen, $\mathrm{CO}$ and $\mathrm{CO}_{2}$, being the smallest for nitrogen (see Fig. 1). An important feature of the voltage contours is that the horizontal lines in the center of the figure represent the region of current transfer (the arc region). Then it is clear that argon has a broader electric transport region than the other gases. Air and oxygen show similar arc regions and the less expanded arcs are $\mathrm{CO}$ and $\mathrm{CO}_{2}$, being nitrogen the narrowest arc. This discussion can be complemented by looking into Figs. 5(a) to 5(f), where current density vectors are plotted for each plasma composition. There, it is seen that effectively argon has by far the most expanded arc than the rest of plasmas for the same flow current and arc length. It is necessary to stress that since the arc current is constant in all calculations the size of the cathode spot is also constant to maintain a current density of $4.4 \times 10^{7} \mathrm{~A} / \mathrm{m}^{2}$ at the spot. Then, it results evident the huge expansion of the argon arc with a bell shape like that contrasts with the narrower bells of the other arcs. Current densities are computed in the model by using the Ohm's law (Eq. (1) and Eq. (2)):

$$
\begin{aligned}
& J_{z}=-\sigma \frac{\partial \Phi}{\partial z} \\
& J_{r}=-\sigma \frac{\partial \Phi}{\partial r}
\end{aligned}
$$

where $J_{z}$ and $J_{r}$ are the axial and radial components of current density respectively, $\sigma$ is the electric conductivity, $z$ and $r$ are the axial and radial coordinates and finally $\Phi$ is the electric potential. Voltage contours suggest that axial component of the current density is higher than the radial component since the axial gradient of $\Phi$ prevails along the arc. Proper integration of axial current density along the radius results in the azimuthal magnetic fields by Ampere's law (Eq. (3)):

$$
B_{\theta}=\frac{\mu_{0}}{r} \int_{0}^{r} J_{z} r d r
$$

where $B_{\theta}$ is the magnetic field and $\mu_{0}$ is the magnetic per- 

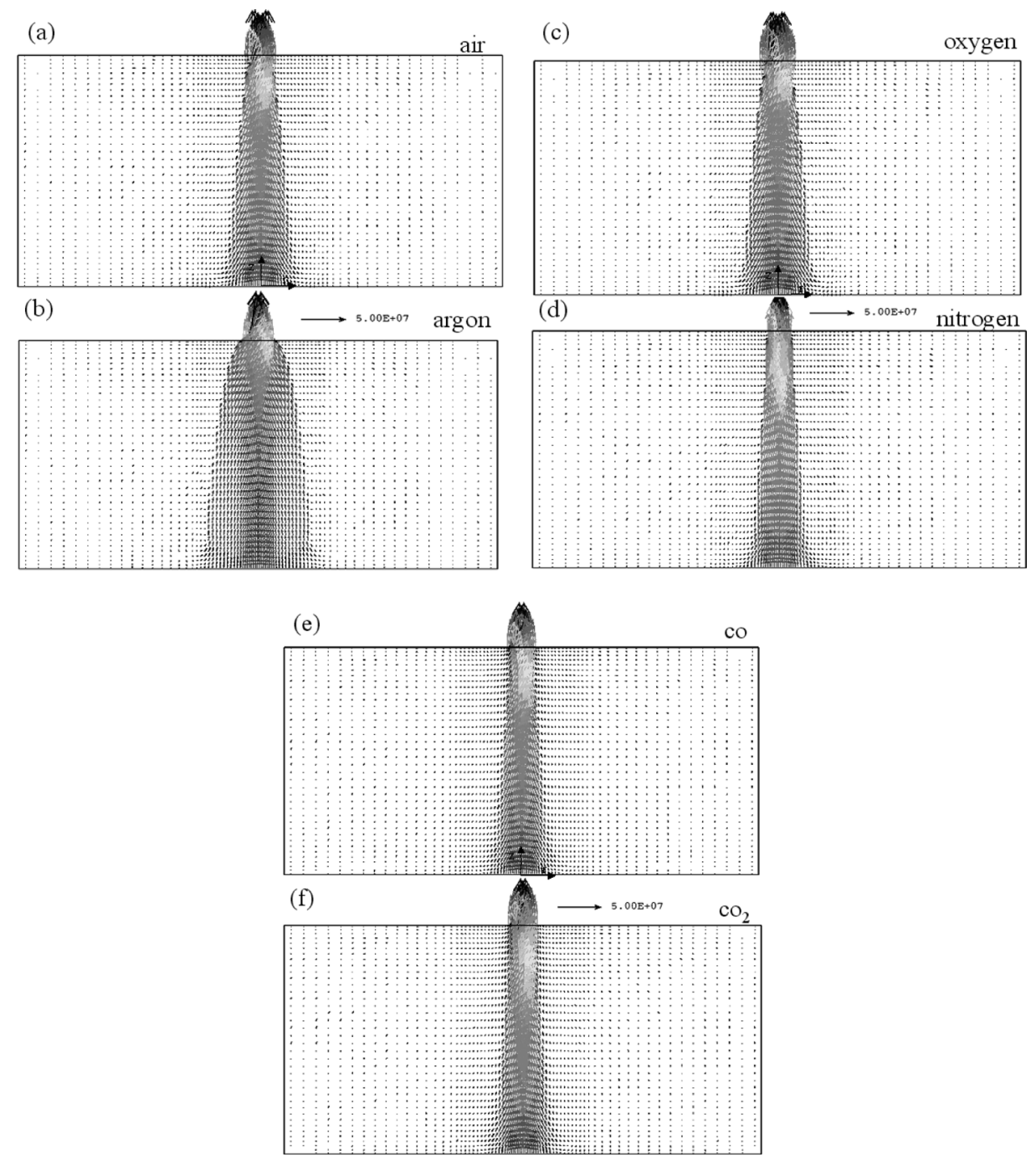

Fig. 5. Current density vectors for electrics arcs of $44 \mathrm{kA}$ current, $0.3 \mathrm{~m}$ length and with different gas atmospheres: (a) air, (b) argon, (c) oxygen, (d) nitrogen, (e) $\mathrm{CO}$, (f) $\mathrm{CO}_{2}$.

meability. The magnetic fields are reported in Figs. 6(a) to 6(f) for all atmospheres considered. Again, argon presents an arc region very expanded resulting in high magnetic field contours and the magnetic field is more extended in radial direction than in the rest of gases. Oxygen and air present also high magnetic fields close to the cathode, while $\mathrm{CO}, \mathrm{CO}_{2}$ and nitrogen show the lowest magnitudes of the magnetic field. Contours of electric potential, magnetic fields and current densities are determined by the temperature dependence of the electric conductivity. Argon has better conductivity than the other plasmas (less electric resistance) and that is the main reason of presenting the greatest arc region, the lowest arc voltage and highest magnetic field.

Figures 7(a) to 7(f) for all gases show temperature contours. Arc temperatures contours are shaped mainly due to the Joule effect (electric conductivity), by the convection of the plasma jet and also by its specific heat. Argon presents a big arc region of low temperatures since their physical properties of electric conductivity and specific heat promote a low Joule heat (low voltage and low electric resistance) which in turns means low arc power. On the contrary $\mathrm{CO}, \mathrm{CO}_{2}$ and in less extent air, oxygen and nitrogen present high temperatures due to a combination of low specific heats and electric conductivities resulting in high voltages and electric resistances which turns in high energy arc (high arc powers).

Finally, Fig. 8 compares the total heat flux transferred from the arc to the bath which is the sum of the main heat transfer mechanisms of convection, radiation and heat transferred by the electric flow (Thompson effect, work function and anode fall). Air and oxygen deliver more heat flux to the bath close to the center and the gas that apparently heat ups the less is argon (under the same arc current and length). However, the important quantity is the integral of the heat flux over the circular bath area of $0.3 \mathrm{~m}$ (the arc attached zone) which is the total heat flowing from the arc to the bath in Watts. Therefore, Fig. 9 shows the total heat flow from the arc to the bath obtained by integration of the heat fluxes over the circular area of $0.3 \mathrm{~m}$, which was chosen to avoid mistakes in the heat flow calculations, since this radius is bigger than the largest arc attached radius of the bath for all arc cases computed in this work. In this plot it can be seen that Air is the gas that heats more the bath followed in second place by the $\mathrm{CO}$ and $\mathrm{CO}_{2}, \mathrm{O}_{2}$ in third place and finally the $\mathrm{Ar}$ is not the gas that heats the less the bath but nitrogen (under the same arc current and arc length). 
ISIJ International, Vol. 49 (2009), No. 6
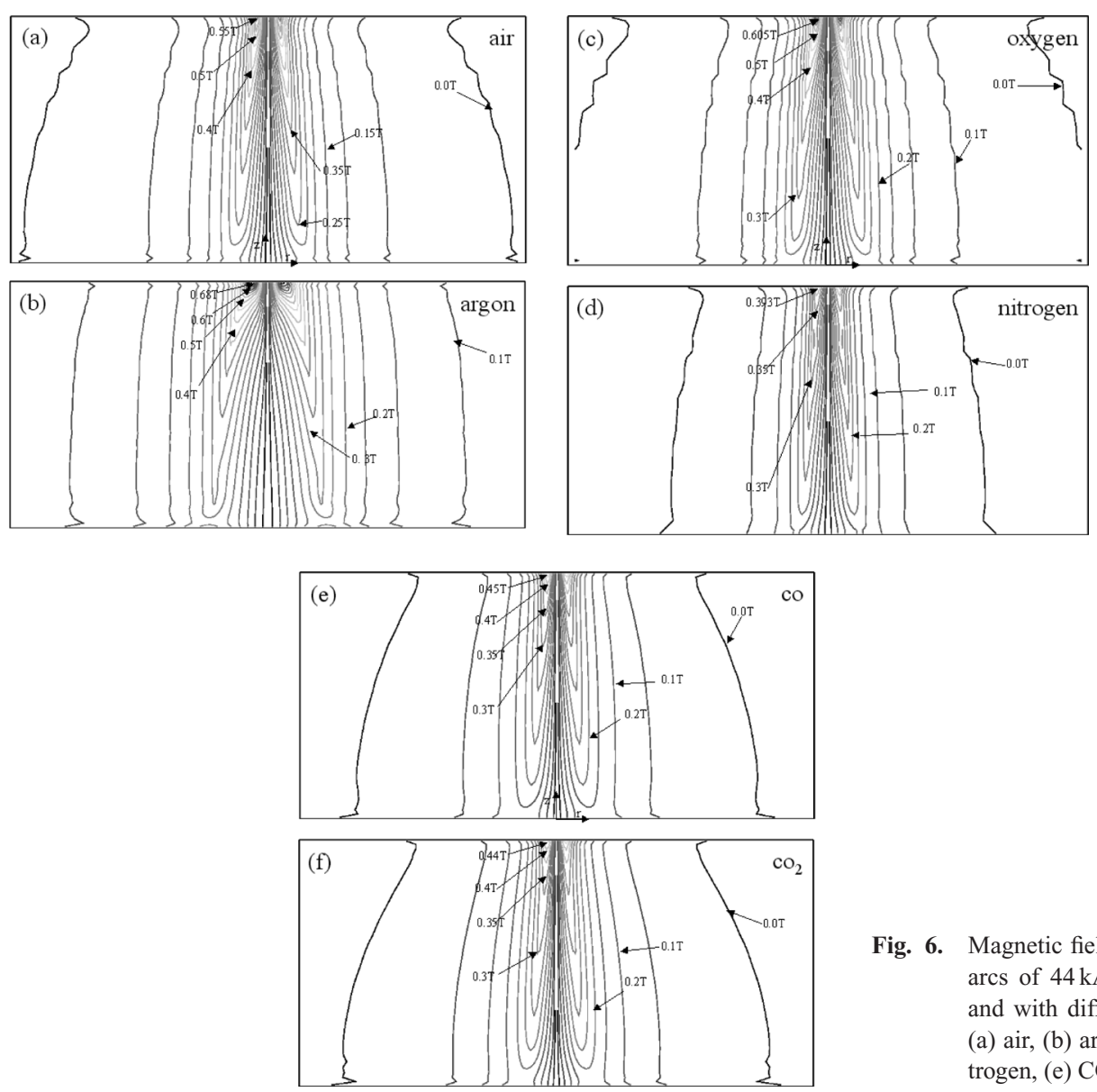

Fig. 6. Magnetic field contours for electrics arcs of $44 \mathrm{kA}$ current, $0.3 \mathrm{~m}$ length and with different gas atmospheres: (a) air, (b) argon, (c) oxygen, (d) nitrogen, (e) $\mathrm{CO}$, (f) $\mathrm{CO}_{2}$.
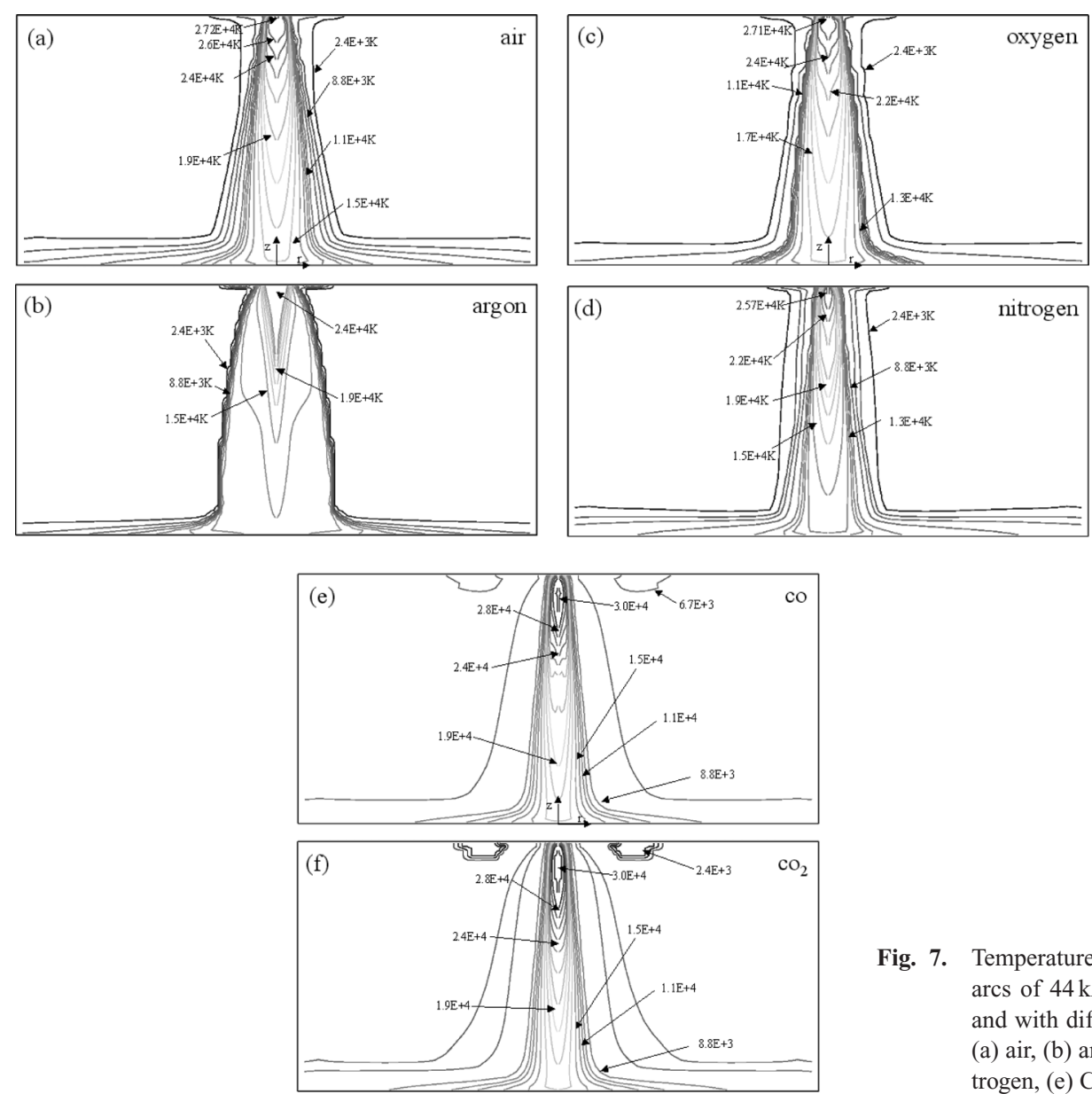

Fig. 7. Temperature contours for electrics arcs of $44 \mathrm{kA}$ current, $0.3 \mathrm{~m}$ length and with different gas atmospheres: (a) air, (b) argon, (c) oxygen, (d) nitrogen, (e) $\mathrm{CO}$, (f) $\mathrm{CO}_{2}$. 


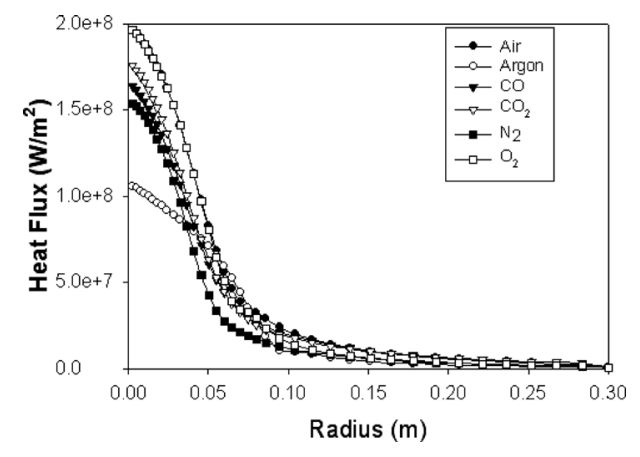

Fig. 8. Total heat flux from arc to bath with current of $44 \mathrm{kA}$ length $0.3 \mathrm{~m}$ and different gas atmospheres (air, argon, oxygen, nitrogen, $\mathrm{CO}$ and $\mathrm{CO}_{2}$ ).

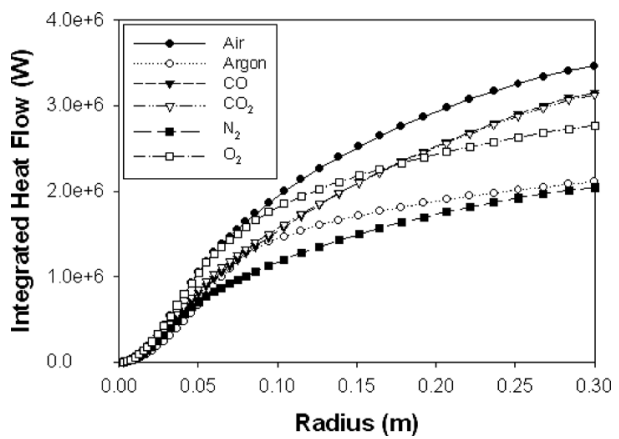

Fig. 9. Total heat flow integrated over the bath surface area in Watts from arc to bath with current of $44 \mathrm{kA}$ length $0.3 \mathrm{~m}$ and different gas atmospheres (air, argon, oxygen, nitrogen, $\mathrm{CO}$ and $\mathrm{CO}_{2}$ ).

Table 1. Electric features and efficiency of the arcs burning in different atmospheres with the same arc length ( $30 \mathrm{~cm})$ and arc current $(44 \mathrm{kA})$.

\begin{tabular}{|c|c|c|c|c|c|}
\hline Gas atmosphere & $\begin{array}{c}\text { Arc length } \\
(\mathrm{cm})\end{array}$ & $\begin{array}{c}\text { Arc current } \\
(\mathrm{KA})\end{array}$ & $\begin{array}{c}\text { Arc Voltage } \\
(\mathrm{V})\end{array}$ & $\begin{array}{c}\text { Arc Power } \\
(\mathrm{MW})\end{array}$ & $\begin{array}{c}\text { Power } \\
\text { efficiency } \\
\text { computed }\end{array}$ \\
\hline Air & 30 & 44 & $\mathbf{7 0 0}$ & $\mathbf{3 0 . 8 0 0}$ & $\mathbf{1 1 . 2 4}$ \\
\hline Argon & 30 & 44 & $\mathbf{5 6 0}$ & $\mathbf{2 4 . 6 4 0}$ & $\mathbf{8 . 5 6}$ \\
\hline $\mathrm{CO}$ & 30 & 44 & $\mathbf{6 7 3}$ & $\mathbf{2 9 . 6 1 2}$ & $\mathbf{1 0 . 6 3}$ \\
\hline $\mathrm{CO}$ & 30 & 44 & $\mathbf{7 4 7}$ & $\mathbf{3 2 . 8 6 8}$ & $\mathbf{9 . 5 1}$ \\
\hline $\mathrm{N}_{2}$ & 30 & 44 & $\mathbf{7 7 1}$ & $\mathbf{3 3 . 9 2 4}$ & $\mathbf{6 . 0 3}$ \\
\hline $\mathrm{O}_{2}$ & 30 & 44 & $\mathbf{6 7 4}$ & $\mathbf{2 9 . 6 5 6}$ & $\mathbf{9 . 3 3}$ \\
\hline
\end{tabular}

Table 1 shows the electric features and efficiency of the arcs burning in different atmospheres but keeping the same arc length $(30 \mathrm{~cm})$ and arc current $(44 \mathrm{kA})$.

Argon is a very special case, since it presents the highest electric conductivity and the lowest heat capacity, this means that the power in the case of argon is the lowest and this gas may be used under long arc length (high power). Air is the most efficient gas followed by $\mathrm{CO}$ and $\mathrm{CO}_{2}$. Nitrogen shows by far the poorest heating behavior. This results are interesting since in a real EAF atmosphere several gases may be present, such as air, $\mathrm{CO}$ and $\mathrm{CO}_{2}$ from decarburization, postcombustion, oxygen lancing and foaming slag practice, as well as other metallic and non metallic vapors coming from the melted charge. It seems obvious that a $\mathrm{CO} / \mathrm{CO}_{2}$ atmosphere will improve the heat transfer from the arc to the bath and save electric energy. This may be a an extra reason to recommend a foaming slag practice by injecting oxygen and carbon fines to promote a $\mathrm{CO} / \mathrm{CO}_{2}$ atmosphere. Also, it seems recommendable to practice the post combustion in order to save electric energy. Argon seems to be interesting for high power conditions with long arc lengths but the additional cost to the process may not be justified with the energy savings produced. Injection of different gases to form a controlled atmosphere is not impossible since holed electrodes may be fabricated to inject gases through them.

\section{Conclusions}

Numerical simulations of DC electric arcs using computational fluid dynamics were performed in this work under six different gas atmospheres and maintaining the same arc length and current. The arc anatomy has been illustrated for each gas.

(1) Air is by far the most efficient gas to heat the bath followed by $\mathrm{CO}$ and $\mathrm{CO}_{2}$. Nitrogen is the less efficient gas.

(2) It was found that an argon atmosphere presents the best electric conductivities and the lowest heat capacity which results in the biggest size of the arc but low arc voltages, resistances, Joule heat, and also low arc powers which mean that the bath is not heated properly at short arc lengths. However this atmosphere may have the advantage of being used with very long arc lengths without exceeding the furnace voltage which may be required in specific operating conditions in industrial furnaces. This flexibility may be beneficial.

(3) Nitrogen has the higher arc power since its electric conductivity is the smallest promoting high arc voltages, high electric resistances and arc powers, but unfortunately this gas is not efficient in transferring energy form the arc to the bath.

(4) Postcombustion, oxygen lancing with carbon fines, and foaming slag are recommended practices since these will set a $\mathrm{CO} / \mathrm{CO}_{2}$ atmosphere that has a good efficiency in transferring energy from the arc to the bath. 
ISIJ International, Vol. 49 (2009), No. 6

\section{REFERENCES}

1) Crude Steel Production 1999, International Iron \& Steel Institute, Brussels, Belgium.

2) Frites and J. Steins: Metall. Plant Technol. Int., 4 (1998), 74.

3) Greis: Metall. Plant Technol. Int., 4 (1998), 84.

4) F.-H. Wang, Z.-J. Jin and Z.-S. Zhu: J. Irons Steel Res. Int., 13 (2006), 7.

5) M. Ushio, J. Szekely and C. W. Chang: Ironmaking Steelmaking, 6 (1981), 279.

6) J. Szekely, J. McKelliget and M. Choudhary: Ironmaking Steelmaking, 10 (1983), 169.

7) F. Qian, B. Farouk and R. Mutharasan: Metall. Mater. Trans. B, 26B (1995), 1057.

8) J. Alexis, M. Ramírez, G. Trapaga and P. Jonson: ISIJ Int., 40 (2000), 1089.

9) M. Ramirez, G. Trapaga and G. Garduño-Esquivel: Metall. Mater.
Trans. B, 35B (2004), 373.

10) J. Park, J. Heberlein, E. Pfender, G. Candler and C. H. Chang: Plasma Chem. Plasma Process., 28 (2008), 213.

11) M. Tanaka, S. Tashiro, T. Satoh, A. B. Murphy and J. J. Lowke: Sci. Technol. Weld. Joining, 13 (2008), 225.

12) P. V. Marques and P. J. Modenesi: Rev. Metal. Madrid, 35 (1999), 292.

13) M. Boulos, P. Fauchais and E. Pfender: Thermal Plasmas-Fundamentals and Applications, Vol. 1, Plenum Press, New York, USA, (1994), 164.

14) G. R. Jordan, B. Bowman and D. Wakelam: J. Phys. D: Appl. Phys., 3 (1969), 1089.

15) B. Bowman: J. Phys. D: Appl. Phys., 5 (1972), 1422.

16) K. C. Hsu, K. Etemadi and E. Pfender: J. Appl. Phys., 54 (1982), 1293.

17) M. Ramirez: PhD Thesis, MIT, Boston, USA, (2000), 64.

18) A. B. Murphy: Plasma Chem. Plasma Process., 15 (1995), 279. 